\title{
INNOVATIVE METHOD FOR THE SELECTION OF ORTHOSES USED IN THE REHABILITATION OF CHILDREN WITH CEREBRAL PALSY
}

\author{
Ż. Pawlak**, B. Ligaj***
}

\begin{abstract}
In rehabilitation, orthopedic equipment is often used to improve the functioning of the musculoskeletal system. The lower limb orthosis, type ankle-foot orthoses is most often used for children with cerebral palsy. Individual adjustment of the orthosis is a particularly important process for achieving the intended rehabilitation goals. Achieving significant effects of the orthotics usage depends on its adjustment to the patient and periodic correction related to the child's development changes in this process are determined by certain factors such as: technological progress, scientific team, higher patients' expectations. The work presents current procedures for the selection of orthoses of children with cerebral palsy and initial modifications supporting the formation of orthoses based on scientific publications.
\end{abstract}

Keywords: Ankle-foot orthosis, cerebral palsy, gait, Finite Element Analysis (FEA)

\section{Introduction}

In the process of evolution, man, as the only species of vertebrates, achieved walking in an upright position (Carsten, 2010). Gait is the basic and most important form of human locomotion, thanks to which man moves. Walking allows one to perform everyday activities, function in social life, and also in the psychological context, the way one moves, expresses people emotion and attitude towards life. The various causes of gait disorder can cause physical, social and psychological limitations.

The most frequent cause of disability among children is cerebral palsy. It occurs with a frequency of $2 \div 3$ cases per 1,000 born children, interfering with, e.g. their gait. One of the most common form to improve the quality of walking in this group is orthopedic equipment. In particular, for children with cerebral palsy (CP), ankle- foot orthoses (AFO) are used (Brehm et al., 2008 and Eddison, Chockalingam 2012).

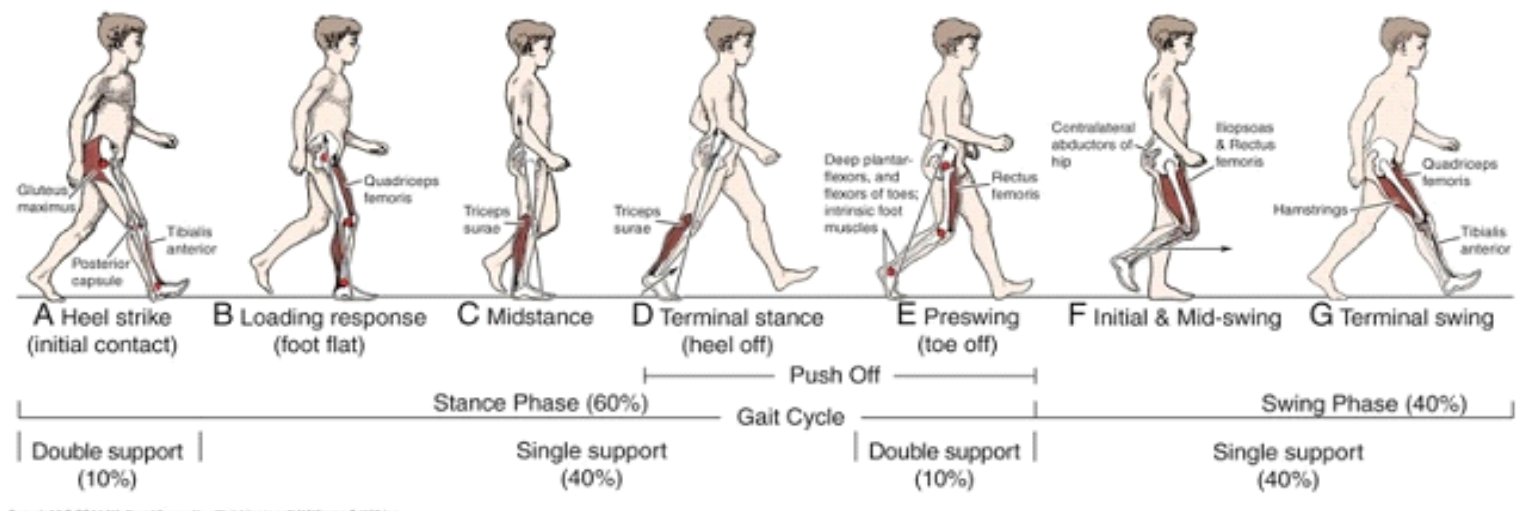

Fig. 1: Gait cycle (Brehm, Harlaar, Schwartz, 2008)

* Assoc. Prof. Żaneta Pawlak: Faculty of Mechanical Engineering, UTP University of Science and Technology in Bydgoszczy, al. Prof. S. Kaliskiego 7, 85-796 Bydgoszcz, PL, e-mail: ze.pawlak@gmail.com

** Prof. Bogdan Ligaj, PhD.: Faculty of Mechanical Engineering, UTP University of Science and Technology in Bydgoszczy, al. Prof. S. Kaliskiego 7, 85-796 Bydgoszcz, PL, e-mail: bogdan.ligaj@utp.edu.pl 
Due to the possibility of correct selection of the orthosis for the child, the patient should be supported by a gait analysis. Comparing patient's walk with cycle of correct physiological gait, it is possible to identify abnormalities. Figure 1 shows the cycle of correct walking with the division into the stance phase and the swing phase (Brehm, Harlaar, Schwartz, 2008).

During the rehabilitation process, orthopedic supplies play an important role. The most often recommended supply is an orthosis covering the foot and the ankle-foot orthosis. The common aims of orthoses: achieving stability in the stance phase, smooth transfer of foot in the phase of swing, setting the foot and limb in the final phase of swing, step length and efficiency of energy (Eddison, Chockalingam, 2012). AFO orthoses appear in different types of constructions:

- DAFO - dynamic ankle foot orthoses (Fig. 2a),

- SAFO - solid or rigid ankle-foot (Fig. 2b),

- HAFO - hinged ankle-foot orthoses (Fig. 2c),

- PLSAFO - posterior leaf spring ankle-foot orthoses (Fig. 2d),

- GRAFO - ground reaction force ankle-foot orthoses) (Fig. 2e).

a)

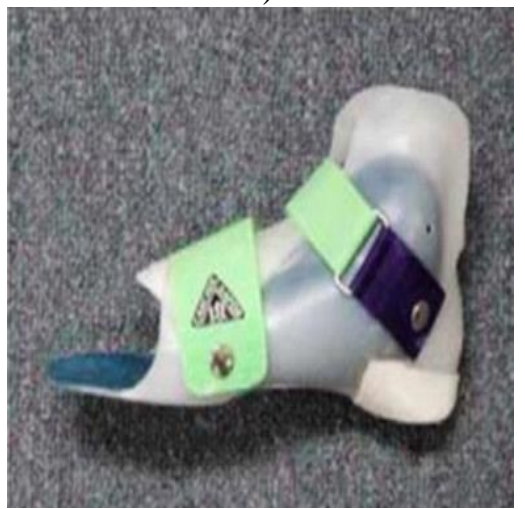

d)

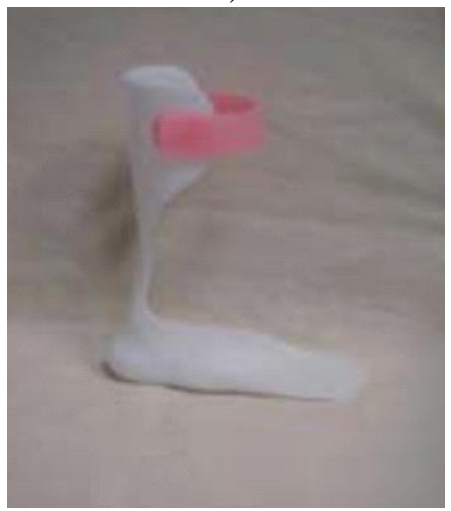

b)

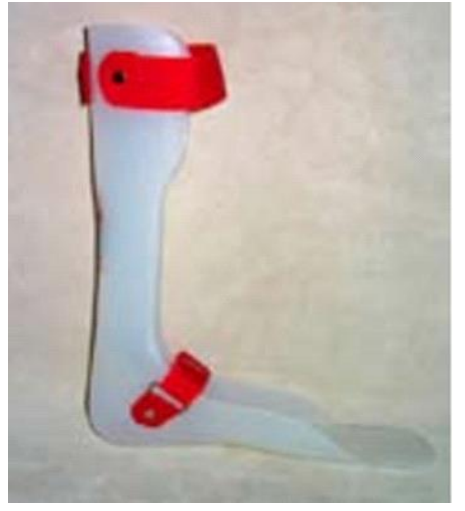

e)

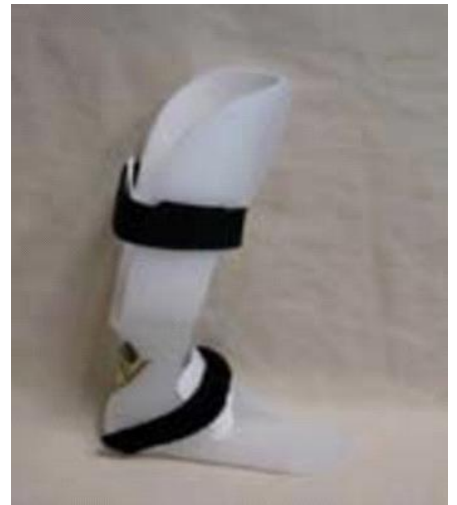

c)

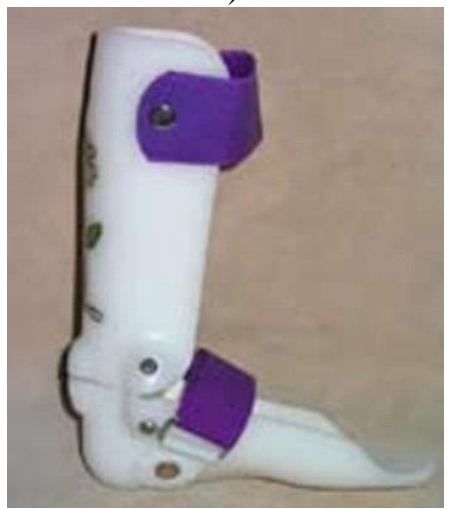

Fig. 2: Examples of different construction solutions for orthoses: $a-D A F O$ (website no.1), $b-S A F O$ (website no.2), c-HAFO (website no.3), d-PLSAFO (website no.4), e-GRAFO (website no.5)

\section{The method of the selection of an orthosis for the patient's needs}

Orthoses can be produced serially or individually, meeting the needs of the patient. The individual adjustment of the orthosis has a significant impact on improving the quality of the gait. Usually, the patient meets an orthotic three times to revive an orthosis. There are stages in order to prepare orthosis.

Stage I: meeting with a physiotherapist or an orthotist who performs physical examination. This study concerns: assessment of gait analysis (in most cases it is a visual assessment), examination of ranges of mobility in the joints of the lower limbs. Then, the measure of the lower limb is taken in the correcting position by casting a plaster cast. On the basis of the patient information obtained, the correction target is determined and the geometrical and mechanical parameters of the orthosis are determined. The physiotherapist, knowing the orthopedic problem and the purpose of correction, makes the choice of the 
best type of AFO orthosis for a given child's gait pattern. The correct influence of the orthosis on the patient depends on the experience of the person conducting the examination.

Stage II: mechanical molding of the plaster of the lower limb, which is: applying corrective points, determining anatomical arches and showing anatomical points. Thermoplastic material is applied to the model made. Next, the orthotics lining is fitted, which is adapted to the developed limb model. After forming the orthosis, the patient tries it on and orthotic makes corrections, at the third meeting the patient receives prepared orthoses.

The traditional method of choosing an orthosis is exposed to a large measurement error, which can lead to a failure in achieving the therapeutic goal which is the improvement of the quality of the child's gait (Jochymczyk-Woźniak, 2015). Manual creation of the plaster model form is exposed to inaccuracy. In addition, the orthotic during the correction should maintain the appropriate rigidity of the given orthosis structure. Therefore, to a large extent, this stage depends on the knowledge and experience of the person making corrections in order to preserve the previously set corrective goal (Bogusławski, Gralewski, Grądzki, 2013).

\section{The method of the selection of an orthosis for the patient's needs}

The most commonly used method of choosing an orthosis for a child with $\mathrm{CP}$ is based on a subjective assessment of a physiotherapist or orthotic. The implementation of an orthosis adapted to the patient's individual characteristics requires the use of modern measurement techniques, modeling of the personalized orthosis and its production.

1. Preparation - a detailed personal and objective interview concerning:

a. Health assessment.

b. 3D limb scan in order to properly select the orthosis geometry.

c. Three-dimensional gait analysis with data interpretation.

d. specification of the purpose of orthopedic correction and selection of the type of orthosis.

This phase is characterized by the use of engineering tools compared to the classical selection of an orthosis. This phase, compared to the classical selection of an orthosis, is characterized by the use of engineering tools in the field of quantitative biomechanical assessment, and not only a qualitative assessment.

2. Modeling and Creation - work in the field of designing and modeling of the virtual model in order to match the orthosis to the limb in the best way and achieve the intended results:

a. The use of CAD / CAM systems for modifying / adjusting geometric parameters.

b. FEA modeling to obtain adequate stiffness and deformation capacity in different orthosis zones at the construction stage.

c. Printout of the designed model with additive methods (3D printing).

In comparison to the traditional orthosis method, the design and modeling analysis to a greater extent and individually to the patient allows to choose the stress-strain parameters of the orthosis (JochymczykWoźniak, 2015).

3. Verification: the patient's gait (evaluation of the correctness of choosing the geometrical features of the orthosis):

a. Comparison of patient's gait without an orthesis and with orthosis to verify the assumed achievements of an individualized orthosis.

Not only a physician, an orthotist, a physiotherapist, but also an engineer specializing in rehabilitation engineering are involved in the process of individualized design. In addition, the team also takes into account the selection of footwear and rehabilitation exercises. Footwear is important for the achieved orthotic results, therefore it is important to modify the sole and heel of the shoe (Eddison., Chockalingam 2012). Exercises allow one to strengthen selected muscle groups to increase the therapeutic effect of the orthosis.

The presented diagram of the innovative, personalized selection of the orthosis is shown in the block diagram (Fig. 3). This schematic describes each stage with the occurring feedback loops. 


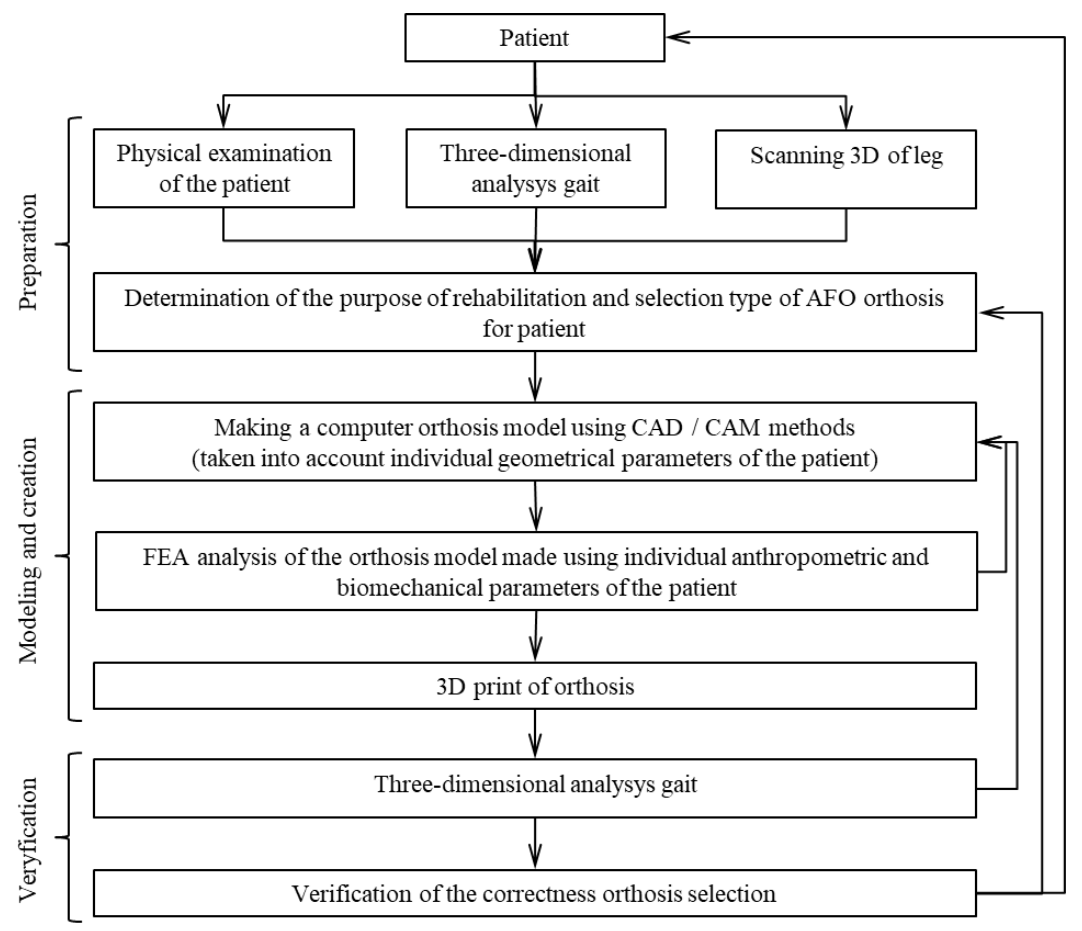

Fig. 3: Block model of alternative production of orthosis

The traditional method of fitting orthoses has a number of disadvantages that can affect the construction of the orthosis. A subjective assessment of the orthotics can generate problems related to the incorrect choice of the type of orthosis, adjustment of the orthosis and incorrect correction. As a consequence, such an orthosis will not fully fulfill its role in the rehabilitation process. Modern technology allows to minimize problems related to designing and adapting orthoses

Many authors emphasize the importance of the process of individual selection of an orthosis. The importance of wearing orthopedic shoes should also be emphasized. It is very common situation when a parent has to choose shoes without the instruction of a specialist, although in the scientific literature it is clearly marked how important is choosing the right shoe for a given correction.

In the process of fitting orthoses, the formula of gait analysis should be disseminated using threedimensional registration systems allowing for the analysis of its geometrical and kinematic parameters. The possibility of gait analysis facilitates the selection of the right type of orthosis as well as the assessment of the correctness of the selection of its geometrical features.

The assumptions of modifying support have an application system that can be used for further research work

\section{References}

Andreijova, M., Dolna, Z., Simsik, D., Kimakova Z., (2012) An analysis of temporal and spatial parameters of human gait. Annals of faculty engineering hunedeora- International Journal of Engineering, vol.3, pp. 49-56.

Bartkowiak, Z., Łuczak-Piechowiak, A., Zgorzalewicz-Stachowiak, M., Idzior,M., Pajor, J., (2008) Metody zaopatrzenia ortopedycznego stosowane u dzieci z mózgowym porażeniem dziecięcym, vol.16, no.4, pp. 99-113.

Bogusławski, G., Gralewski, J., Grądzki, R., (2013) Modelowanie ortezy kończyny dolnej. Aktualne Problemy Biomechaniki 7, pp. 23-26.

Brehm, M., Harlaar, J., Schwartz, M., (2008) Effect of ankle orthoses on walking efficency and gait in children with cerebral palsy. J Reahabil Med, vol.40, no. 7, pp. 529-534.

Carsten, N., (2010) The evolution of the upright posture and gait-a review and a new synthesis. Naturwissenschaften, vol. 97, pp. 241-263.

Eddison, N., Chockalingam, N., (2012) The effect of tuning ankle foot orthoses-footwear combination on the gait parameters of children with cerebral palsy. Posthetics and Orthotics International, vol.37, no.2, pp. 95-107.

Jochymczyk-Woźniak, K., Chuchnowska, I., Wolański, W. et al., (2015) Badanie wspomagające przygotowanie spersonalizowanych ortez typu Afo/Dafo, Modelowanie Inżynierskie, 56, pp. 40-47.

Website no.1-5: Using Evidence to Select an Ankle foot Orthosis (AFO) for Children With Cerebral Palsy FACT SHEET Section on Pediatrics, APTA, 2008 